\title{
Hepatotoxicity associated with use of D-penicillamine in rheumatoid arthritis
}

\author{
JERRY ROSENBAUM, ${ }^{1}$ WARREN A. KATZ, ${ }^{2}$ AND \\ H. RALPH SCHUMACHER ${ }^{3}$
}

From the Division of Rheumatology, Division of Medicine, Medical College of Pennsylvania, Philadelphia, USA

SUMMARY Two patients with rheumatoid arthritis developed evidence of hepatotoxicity while receiving D-penicillamine. Both recovered after withdrawal of the drug. These cases and a review of the literature suggested that hepatotoxicity, though rare, should be added to the list of adverse reactions to D-penicillamine.

D-penicillamine has been used for the treatment of rheumatoid arthritis for over 10 years. The United Kingdom Multicentre Trial Group (1973) and several recent reports by Jaffe (1978) and others have added impetus to its application. It is the drug of choice for the treatment of patients with Wilson's disease or cystinuria and is also used in chronic aggressive hepatitis, scleroderma, macroglobulinaemia, and heavy metal toxicity. Several untoward reactions have been reported and are almost always reversible with discontinuation of the drug. This report describes hepatotoxicity, an uncommon complication in 2 patients treated with D-penicillamine for rheumatoid arthritis.

\section{Case 1}

A 43-year-old Caucasian woman developed seropositive rheumatoid arthritis at age 32 one month after a normal delivery. Polyarthritis began in the fingers and knees and soon involved the neck, shoulders, and elbows. She had an excellent response to intramuscular gold, sodium thiomalate, and tolerated it without difficulty until it was discontinued in 1970 because she again became pregnant. From 1970 to 1975 she was in clinical remission and received no therapy.

In November 1975 polyarthritis and morning

Accepted for publication 30 April 1979.

${ }^{1}$ Division of Rheumatology, Medical College of Pennsylvania, 3300 Henry Avenue, Philadelphia, PA, 19129, USA.

2 Medical College of Pennsylvania, Philadelphia, PA, and Medical College of Pennsylvania, USA.

3 VA Hospital of Philadelphia and University of Pennsylvania School of Medicine, Philadelphia, PA, USA.

Correspondence to Dr J. Rosenbaum. stiffness recurred, with no relief from up to $4.8 \mathrm{~g}$ of aspirin daily. Gold was reinstituted but had to be discontinued without benefit after the development of a rash. Aspirin 4.2 g per day, was continued. D-penicillamine, $250 \mathrm{mg}$ daily, was initiated on 13 May, 1977. There was no history of cholelithiasis, penicillin allergy, or hepatitis. Complete blood count, platelet count, liver function tests and urine analysis were within normal limits.

Two months later routine physical examination was unchanged. Neither fever, icterus, nor hepatomegaly was noted. There was no known exposure to hepatitis. Laboratory evaluation at that time showed a lactic dehydrogenase (LDH) concentration of $\mathbf{4 0 5}$ units (normal 140-270 units), serum glutamic oxaloacetic transaminase (SGOT) of 440 units (normal 9-22 units), an alkaline phosphatase of 70 Bodansky units (normal 12-40 Bodansky units), a normal complete blood count (CBC), platelet count, creatine phosphokinase, urine analysis, and bilirubin. A test for hepatitis-associated antigen was negative.

D-penicillamine was stopped while aspirin was continued. The SGOT level gradually fell to 46 by 29 July, 1977, and on 23 September, 1977 it was 32. Therapy with D-penicillamine was then reinstituted; during the next 2 weeks the SGOT increased to 91 units. CBC was normal with $2 \%$ eosinophils. D-penicillamine was again discontinued, and by 6 December, 1977 the SGOT was 13 units. Active polyarthritis persists with a rheumatoid factor titre of $1: 5120$.

\section{Case 2}

A 60-year-old man presented with rheumatoid 
arthritis, first appearing in the wrists, ankles, and knees. In 1972 gold, sodium thiomalate, was begun, but was discontinued after 2 years because of lack of efficacy. In 1974 triamcinolone $12 \mathrm{mg}$ daily was started and gradually tapered over 2 years to $6 \mathrm{mg}$. In October 1977 he was given tolmetin 1200 mg daily after a short unsuccessful trial of naproxen.

In January 1977 he was admitted to the Moss Rehabilitation Hospital for physical therapy and the initiation of D-penicillamine. Penicillin 20 years earlier had induced an erythematosus macular rash and had not been taken thereafter. Neither the liver nor spleen was enlarged. Bilateral elbow flexion contractures and synovitis of the wrists, metacarpophalangeal joints, and knees were present. Rheumatoid nodules were palpable at each olecranon. Serum electrolytes, liver function tests, muscle enzymes, and urine analyses were within normal limits. The latex fixation test for rheumatoid factor was $1: 1280$.

D-penicillamine $250 \mathrm{mg}$ daily was started. Two weeks later he developed light stools, dark urine, and icteric sclerae. Neither fever nor rash was noted. The liver was enlarged to $12 \mathrm{~cm}$. Laboratory tests revealed a bilirubin of $2 \cdot 2 \mathrm{mg} / 100 \mathrm{ml}$, alkaline phosphatase of 335 Bodansky units (normal 13-45), SGOT of 128 units (normal 9-22), LDH of 222 units (normal 140-225), and serum glutamic pyruvic transaminase of 238 units (normal 11-66). Hepatitis-associated antigen was not detected. Complete blood count revealed no eosinophilia.

After the discontinuation of D-penicillamine and tolmetin the patient gradually improved, with return to normal of bilirubin and liver enzymes in 1 month. The alkaline phosphatase gradually became normal over 9 months. Active synovitis subsequently responded to hydroxychloroquine.

\section{Discussion}

Hepatotoxicity recondary to D-penicillamine has been reported infrequently. In a recent study of D-penicillamine toxicity in 63 patients with rheumatoid arthritis hepatotoxicity was not observed (Weiss et al., 1978). Liver injury in one patient after D-penicillamine was associated with thrombocytopenia, pruritus, and urticaria. Histological examination of the liver in that case revealed hepatocellular necrosis and cholestasis after 1 month of penicillamine therapy (Hennemann et al. 1975). Cholestatic jaundice has appeared with combination therapy of D-penicillamine and indomethacin (Siegmund, 1976). Rau et al., (1972) reported treating a patient with systemic sclerosis with $1.8 \mathrm{~g}$ of penicillamine daily. Three weeks after therapy was started the patient developed jaundice accompanied by fever, pruritus, rash, nausea, and slight eosinophilia. Penicillamine was discontinued. The rash and jaundice disappeared, and the laboratory findings became normal 2 weeks later. The authors concluded that a drug-induced hepatitis of the cholestatic type had been caused by D-penicillamine. Cholestatic jaundice developed also in a patient with rheumatoid arthritis 4 weeks after penicillamine was added to his regimen of salicylates and corticosteroids. He died in acute renal failure (Barzilai et al., 1978). Hepatocellular damage occurred in a 13-year-old girl with rheumatoid arthritis after combination therapy of D-penicillamine and benorylate (an ester of acetylsalicylic acid and acetominophen) (Sacher and Thaler, 1977).

Hepatic damage caused by salicylates has been reported (Garber et al., 1975), but the first patient's continuing salicylate therapy and rising SGOT after D-penicillamine rechallenge argue against salicylate hepatotoxicity as the sole factor in her enzyme changes. To our knowledge there is no known association of tolmetin and hepatoxicity. The only hepatic damage attributed to corticosteroids is fatty infiltration (Klatskin, 1969).

The suspected mechanisms of D-penicillamine toxicity include hypersensitivity; inhibition of pyridoxine metabolism especially by the L-isomer, which may contaminate the product; immune complex deposition seen in nephropathy (Jaffe, 1968; Lachmann, 1968); and possible localised areas of copper deficiency, with subsequent interference with collagen and elastin formation. D-penicillamine must also be considered a potent inducer of autoantibodies and autoimmune disease.

We are uncertain if these cases represent liver damage in the framework of a direct toxic or an idiosyncratic drug reaction. The possibility of hepatotoxicity in patients treated with D-penicillamine should be considered.

\section{References}

Barzilai, D., Dickstein, G., Enat, R., Bassan, H., Lichtig, C., and Gelle, B. (1978). Cholestatic jaundice caused by D-penicillamine. Annals of the Rheumatic Diseases, 37, 98-100.

Garber, E., Craig, R. M., and Bahu, R. M. (1975). Aspirin hepatotoxicity. Annals of Internal Medicine, 82, 592-593.

Hennemann, H. H., Hubertus, H., and Stocker, W. G. (1975). Schuere Nebenwirkungen bei der Therapie mit Dpenicillamine. Deutsche medizinische Wochenschrift, 100, 1634-1638.

Jaffe, L. A. (1968). Effects of penicillamine on the kidney and on taste. Postgraduate Medical Journal (suppl), 15.

Jaffe, L. A. (1978). D-penicillamine. Bulletin on the Rheumatic Diseases, 28, 948-952.

Klatskin, G. (1969). Toxic and drug induced hepatitis. In Diseases of the Liver, 3rd edn., p. 553. Edited by L. Schiff. Lippincott: Philadelphia and Toronto. 


\section{Rosenbaum, Katz, Schumacher}

Lachmann, P. J. (1968). Nephrotic syndrome from penicillamine. Postgraduate Medical Journal (suppl.), 23.

Multi-Centre Trial Group (1973). Controlled trial of Dpenicillamine in severe rheumatoid arthritis. Lancet, 1 , 275-280.

Rau, R., Weber, S., and Böni, A. (1972). Allergisch-toxische Leberschadigung durch D-penicillamin. Schweizerische medizinische Wochenschrift, 102, 1226-1228.

Sacher, M., Thaler, H. (1977). Toxic hepatitis after thera- peutic doses of benorylate and D-penicillamine. Lancet, $1,481-482$.

Siegmund, H. (1976). Intrahepatische Cholestase nach einer Behandlung mit D-penicillamin and Indometacin. Medizinische Welt, 27, 172-173.

Weiss, A. S., Markenson, J. A., Weiss, M. A., and Kammerer, W. H. (1978). Toxicity of D-penicillamine in rheumatoid arthritis. American Journal of Medicine, 64, 114120. 